\title{
PRÁTICAS DO DISCLOSURE VOLUNTÁRIO SOCIOAMBIENTAL EM COOPERATIVAS AGROPECUÁRIAS BRASILEIRAS
}

\author{
Data de submissão: 04/05/2018 \\ Aceite: $26 / 09 / 2018$ \\ Lorenna Gabriella Novaes Santana ${ }^{1}$ \\ Jose Alexandre dos Santos ${ }^{2}$ \\ Marta Pagán Martínez ${ }^{3}$ \\ Rosamaria Cox Moura Leite Padgett ${ }^{4}$
}

\section{RESUMO}

O objetivo deste artigo é descrever o disclosure voluntário socioambiental em cooperativas agropecuárias brasileiras. A fim de atingir o objetivo traçado, foram analisados os relatórios anuais presentes nos websites de uma amostra não-probabilística das maiores cooperativas agropecuárias brasileiras, referentes ao período de 2015. Para a análise dos dados, foram utilizadas as médias por subcategoria e três índices de avalição de disclosure: Índice de Disclosure (ID), Índice de Disclosure das Empresas (IDE) e Índice Geral de Disclosure das Empresas (IGDE), Índice Geral de Disclosure social (IGDs). Além disso, foi desenvolvido um quinto índice de avaliação do disclosure: o Índice Geral de Disclosure ambiental (IGDa). Os resultados obtidos permitem afirmar que há mais divulgações de informações sociais do que ambientais, com destaque para, relação com empregados, preocupação com a comunidade e com educação, e que ainda falta muito para alcançar uma boa aderência de disclosure voluntário socioambiental pelas cooperativas agropecuárias analisadas.

Palavras-chave: transparência, divulgação de informação, open data, variáveis socioambientais, agronegócio.

\footnotetext{
1 Possui graduação em andamento em Bacharel em Ciências Contábeis pela Universidade Federal de Mato Grosso do Sul, UFMS, Brasil. E-mail: loresgabriella@gmail.com

2 Possui graduação em Administração e mestrado em Administração pela Universidade Federal de Mato Grosso do Sul, UFMS, Brasil. E-mail: prof.jose.alexandres@gmail.com

3 Possui graduação em Humanidades pela Universidad de Castilla - La Mancha, UCLM, mestrado em Humanidades Digitales pela UCLM e doutorado em Técnicas e Métodos em Informação e Documentação pela Universidad de Murcia, UM, Espanha e pós-doutorado em Administração pela Universidade Federal de Mato Grosso do Sul, UFMS, Brasil.

E-mail: pagan.marta@gmail.com

4 Possui graduação em Administração pela Universidade Federal de Santa Catarina, UFSC, Brasil, mestrado em Desarrollo Local Sostenible y Economia Social pela Universidad de Huelva, UHU, Espanha e doutorado em Economia de la Empresa pela Universidad de Salamanca, USAL, Espanha. Docente do Programa de Pós-Graduação em Administração da Escola de Administração e Negócios da Universidade Federal de Mato Grosso do Sul, UFMS, Brasil. E-mail: rosamariamouraleite@gmail.com
} 


\section{INTRODUÇÃO}

A contabilidade tem como objetivo principal fornecer informações aos usuários em geral com a finalidade de auxiliar na tomada de decisões econômicas com segurança, fidedignidade e relevância em tempo hábil (IUDícIBUS, 2010). O disclosure não é um princípio contábil, porém, está relacionado ao objetivo da contabilidade no que tange à evidenciação das informações produzidas por essa ciência em seus relatórios (COMITÊ DE PRONUNCIAMENTOS CONTÁBEIS-CPC, 2016). Dessa forma, disclosure pode ser interpretado como a evidenciação de informações contábeis quantitativas ou qualitativas publicadas pela empresa por meio de canais formais ou informais de divulgação (GIBBINS, RICHARDSON e WATERHOUSE, 1990).

Bushman et al. (2004) relacionam o conceito de disclosure (evidenciação) com o conceito de transparência corporativa, os quais a definem como a disseminação de informação relevante e confiável acerca do desempenho operacional, financeiro, das oportunidades de investimento, da governança, dos valores e riscos. Assim, para esses autores, a transparência corporativa é um instrumento de divulgação de informações específicas da empresa para seus usuários externos.

A evidenciação total de informações (full disclosure) não é vista na prática (LANG e LUNDHOLM, 2000). Isso se deve ao fato de a geração e divulgação de informações implicarem custos para a empresa, tornando o disclosure total, parcial ou nulo, dependendo do custo/benefício de divulgar as informações (HOSSAIN, 2008). Para Verrecchia (2001), a ausência de custos de divulgação pressupõe uma divulgação completa. Na mesma linha de raciocínio, Yamamoto e Salotti (2006) afirmam que na medida em que os custos aumentam, o disclosure tende a diminuir. Dessa forma, nota-se que quando determinada empresa divulga uma informação voluntariamente espera-se que os benefícios dessa divulgação superem seus custos (VERRECCHIA, 2001). Assim, o disclosure voluntário só ocorre quando há mais benefícios do que custos para as empresas (DYE, 2001).

As organizações cooperativas possuem sete princípios fundamentais, os quais dependem fortemente de uma boa transparência para sua efetiva aplicação. Destacam-se: gestão democrática; educação, formação e informação; interesse pela comunidade. Para a efetiva aplicação desses princípios bem como para uma melhor solidez no mercado, é primordial que seus membros e a comunidade tenham plena visão do que se passa na cooperativa. Bialoskorski Neto (2007) afirma em sua obra que a função-objeto de uma cooperativa é distribuir os resultados aos seus associados e traçar uma estratégia de distribuição de resultados econômicos por meio de melhores preços de aquisição de produtos e melhor preço de venda dos produtos fim da cooperativa.

Tendo em vista que a Teoria do Disclosure Voluntário, também conhecida como Divulgação baseada em Julgamento (YAMAMOTO e SALOTTI, 2006), atribui o disclosure a um acontecimento endógeno, no qual os gestores e/ou as empresas possuem benefícios econômicos para evidenciar, ou não, informações de forma voluntária, visando atender às demandas dos usuários externos das demonstrações contábeis (VERRECCHIA, 2001) bem como a relevância econômica e social das cooperativas, o problema de pesquisa é: de que maneira as cooperativas agropecuárias brasileiras divulgam informações socioambientais?

Orientado por esta questão, o objetivo desta pesquisa é descrever o disclosure socioambiental de cooperativas agropecuárias brasileiras.

Justifica-se a realização dessa pesquisa devido à escassez de estudos sobre as práticas de disclosure voluntário nas cooperativas agropecuárias, à relevância das cooperativas no desenvolvimento agropecuário dentro e fora do contexto brasileiro, e à importância do disclosure voluntário de informações no âmbito das cooperativas no setor do agronegócio, diminuindo a assimetria e brecha informacional e, ainda, amenizando os problemas com o risco moral (MURCIA e DOS SANTOS, 2009). 
Assim, a principal contribuição da pesquisa foi a descrição do disclosure voluntário socioambiental de cooperativas agropecuárias brasileiras, bem como a utilização de uma métrica abrangente e representativa que permite mensurar o nível de disclosure voluntário das cooperativas agropecuárias, contribuindo para a literatura brasileira sobre o tema e para futuras pesquisas.

\section{REVISÃO DA LITERATURA}

Na revisão da literatura será apresentado o disclosure voluntário bem como as vantagens em aplicá-lo, um breve histórico das cooperativas e os princípios que as conduzem.

\subsection{Disclosure Voluntário}

A contabilidade, na qualidade de ciência social aplicada, tem uma metodologia especialmente concebida para captar, registrar, acumular, resumir e interpretar os fenômenos que afetam às situações patrimoniais, financeiras e econômicas de qualquer ente, seja este pessoa física, entidade de finalidade não lucrativa, empresa, ou pessoa de Direito Público. Esta área tem um campo de atuação muito amplo e foi desenvolvida inicialmente devido ao surgimento do capitalismo e a necessidade de mensurar os acréscimos ou decréscimos dos investimentos iniciais alocados a alguma exploração comercial ou industrial (IUDíCIBUS, 1998).

Hendriksen (1999) afirma em sua obra que os objetivos da contabilidade podem contemplar um conjunto básico de informações que satisfaçam igualmente bem a todos os usuários, independente da natureza das informações, ou a contabilidade deveria evidenciar informações completamente diferentes para sanar as necessidades de cada usuário separadamente. Para ludícibus (1980), o objetivo da contabilidade envolve aspectos de produtividade e sociais, sendo essa divulgação de informações adicionais que incluem, entre outros, níveis de emprego da entidade, tipos de treinamento, demonstração de valor adicionado. Já na visão de Lopes, ludícibus e Martins (2005), um dos principais objetivos da contabilidade é contribuir para a redução da assimetria informacional existente entre os usuários internos e externos da entidade.

Contudo, é cabível afirmar que o disclosure é intrínseco às características qualitativas da informação contábil - compreensibilidade, relevância, confiabilidade e comparabilidade (IASC, 2001), buscando torná-la mais útil e aumentando a capacidade de avaliação preditiva do usuário. (MEDEIROS e QUINTEIRO, 2005). Dantas, Zendersky e Niyama (2008) ressaltam que para alcançar a transparência pretendida com o disclosure, a instituição deve divulgar informações qualitativas e quantitativas que possibilitem aos usuários formar uma compreensão das atividades desenvolvidas e dos seus riscos, observando os aspectos de tempestividade, detalhamento e relevância necessários, demonstrando assim, a verdadeira situação das entidades, o que potencializa a capacidade de avaliação preditiva.

A divulgação de informações pelas empresas pode se dar de forma voluntária ou obrigatória. O disclosure obrigatório é aquele no qual as empresas são obrigadas por força de lei a divulgar algumas informações consideradas relevantes aos usuários, mesmo que não traga os benefícios esperados pela empresa, gerando custos para a elaboração. Já o disclosure voluntário é aquele no qual a empresa divulga as informações por acreditar que traz benefícios aos usuários internos e externos, como os investidores existentes e em potencial, superando os custos de produção das informações (YAMAMOTO e SALOTTI, 2006).

A sociedade exerce pressão para que as empresas divulguem informações socioambientais, posto que comunicar as ações funciona como um instrumento de legitimação. Além disso, o crescimento no nível de disclosure demonstra uma preocupação das empresas em como a socie- 
dade tem percebido suas ações (SAMPAIO et. al, 2012). As empresas têm incentivos para divulgar informações socioambientais quando elas são positivas e esperam que essa ação traga legitimidade para a organização ou atenda ao anseio de algum stakeholder (RUFINO e MACHADO, 2015).

Para obter legitimação das práticas de responsabilidade socioambiental é necessária a publicação de informações de boa qualidade em meios de comunicação adequados (COSTA et al., 2013). É importante destacar que os relatórios não financeiros contribuem para demonstrar a transparência face aos stakeholders. Nesse sentido, os relatórios de sustentabilidade são fundamentais para efetivação da comunicação com as partes interessadas (AMRAN; LEE; DEVI, 2014).

As cooperativas, apesar de em seus princípios demonstrarem fortes preocupações com a transparência, têm exigências de divulgação menores que as empresas de capital aberto. Falta de incentivos para divulgarem, alto custo de publicação, a ausência de leis e a falta de demanda para a informação podem ocasionar um nível reduzido de disclosure de informações sociais e ambientais (LORZA, 2014).

\subsection{Cooperativas}

As cooperativas são sustentadas pela cooperação, e cooperar é agir de forma coletiva com os outros, trabalhar de forma conjunta em prol de um mesmo objetivo (GAWLAK e RAZKE, 2010). A prática cooperativista contribui para a educação das pessoas e ajuda a desenvolver uma mentalidade mais flexível, participativa, humana e solidária, visto que, para atingir seus objetivos as cooperativas sustentam-se em valores de autoajuda, autoresponsabilidade, democracia, igualdade, equidade e solidariedade. (INTERNATIONAL CO-OPERATIVE ALLIANCE, 2013).

As cooperativas estão presentes em todos os setores da economia e são de fundamental importância para a criação de empregos. Segundo a Organização das Nações Unidas para Agricultura e Alimentação - FAO (2012), foram mais de 100 milhões de empregos diretos e indiretos em todo o mundo, mobilização de recursos, geração de investimentos, além da contribuição para o desenvolvimento econômico e social dos povos. Dessa maneira, cabe ressaltar que cooperativa é a "associação autônoma e voluntária para atender às suas necessidades e aspirações comuns, econômicas sociais e culturais, por meio de empreendimento de propriedade comum e de gestão democrática" (OIT, 2012).

As cooperativas são regidas por sete princípios fundamentais, apresentados no Quadro 1:

Quadro 1. Princípios que regem as cooperativas.

\begin{tabular}{|c|l|}
\hline Princípios & \multicolumn{1}{c|}{ Definição } \\
\hline $\begin{array}{c}\text { Adesão voluntária e } \\
\text { livre }\end{array}$ & $\begin{array}{l}\text { As cooperativas são abertas a todas as pessoas aptas a utilizar os seus serviços } \\
\text { e a assumir responsabilidades como membros, sem discriminação de gênero, } \\
\text { cor, política, religião ou classe social. }\end{array}$ \\
\hline $\begin{array}{c}\text { Gestão democrática } \\
\text { O controle da cooperativa é realizado por seus membros, que são convidados } \\
\text { a compartilhar todas as decisões. Cada associado tem direito a um voto, inde- } \\
\text { pendentemente de seu capital no empreendimento. }\end{array}$ \\
\hline $\begin{array}{c}\text { Participação econômica } \\
\text { dos membros }\end{array}$ & $\begin{array}{l}\text { Cada associado contribui para a constituição do capital de suas cooperativas, } \\
\text { controlando-o democraticamente; }\end{array}$ \\
\hline $\begin{array}{c}\text { Autonomia e indepen- } \\
\text { dência }\end{array}$ & $\begin{array}{l}\text { As cooperativas são organizações autônomas, de ajuda mútua, controladas por } \\
\text { seus membros de forma independente. }\end{array}$ \\
\hline $\begin{array}{c}\text { Educação, formação e } \\
\text { informação }\end{array}$ & $\begin{array}{l}\text { As cooperativas promovem a educação e a formação de seus associados para que } \\
\text { estes possam contribuir, cada vez mais, com o crescimento do empreendimento. }\end{array}$ \\
\hline $\begin{array}{c}\text { Intercooperação } \\
\text { Interesse pela comuni- } \\
\text { dade }\end{array}$ & $\begin{array}{l}\text { As cooperativas devem ajudar-se entre si, trabalhando - sempre que possível } \\
\text { - em conjunto. A lógica é unir forças, pensamento oposto à competição vivida } \\
\text { pelas empresas tradicionais. }\end{array}$ \\
\hline $\begin{array}{c}\text { As cooperativas trabalham para o desenvolvimento sustentado das suas comu- } \\
\text { nidades e devem tomar todas as suas decisões de maneira socialmente res- } \\
\text { ponsável. }\end{array}$ \\
\hline
\end{tabular}

Fonte: Elaborado pelos autores com base na OCB (2013). 
Dessa maneira, cabe mencionar que a transparência está diretamente relacionada à credibilidade, confiança, responsabilidade social, ética, ela eleva a qualidade democrática, aumentando a participação do coletivo nas cooperativas. Dessa forma, nota-se a importante relação entre os princípios cooperativistas, principalmente a adesão voluntária e livre, gestão democrática, educação, formação e informação, e o interesse pela comunidade, com o disclosure socioambiental (SCHULTZ et al., 2013).

Portanto, espera-se que as cooperativas, por força dos princípios, realizem ações de responsabilidade social e ambiental e divulguem de forma voluntária as informações, principalmente para serem legítimas na comunidade da qual fazem parte.

\section{METODOLOGIA}

Para atingir o objetivo proposto nesse estudo, desenvolveu-se uma pesquisa teórico -empírico de caráter descritivo. Considera-se descritiva uma vez que se pretende descrever o disclosure socioambiental de cooperativas agropecuárias brasileiras mediante a análise quantitativa dos dados coletados.

\subsection{Seleção da amostra e coleta de dados}

A seleção da amostra não-probabilística, foi obtida do ranking das "400 maiores empresas do agronegócio" do ano de 2016 publicado pela revista Exame, o qual classifica as 400 maiores empresas (entre elas cooperativas, empresas de capital aberto, etc.). Foram selecionadas as 62 cooperativas presentes no ranking. Após selecionada a amostra, optou-se por investigar os balanços sociais, relatórios de sustentabilidade, relatório da administração e/ou relatório anual presentes nos sites dessas cooperativas, pois a forma de divulgação desses relatórios, na atualidade, é mais comum online do que em revistas ou jornais da área.

Durante o processo de coleta de dados, verificou-se que uma cooperativa não possui website, 30 possuem website, mas não divulgam nenhum tipo de informações socioeconômicas em relatórios, 08 cooperativas divulgam relatórios em período diferente do pesquisado e 23 cooperativas divulgam relatórios dos quais foram extraídas informações referentes ao ano de 2015 , sendo essas 23 cooperativas a amostra da pesquisa.

\subsection{Medida de Disclosure Voluntário}

Os procedimentos adotados nesta pesquisa têm como base a métrica de disclosure voluntário desenvolvida por Murcia (2009). Murcia (2009) pesquisou os fatores que explicam o nível de disclosure voluntário das companhias abertas no Brasil, avaliando as 100 maiores companhias abertas não-financeiras e obteve como resultado que as maiores empresas do setor elétrico, que possuem American Depositary Receipts (ADRs) nos níveis II e III na Bolsa de Nova lorque (NYSE) e que aderem aos níveis diferenciados de governança corporativa da Bolsa de São Paulo (Bovespa), possuem, em média, um maior nível de disclosure voluntário.

Ressalta-se que apesar do estudo do Murcia (2009) ter sido desenvolvido para empresas de capital aberto, a metodologia do estudo para mensurar o disclosure voluntário será utilizada para desenvolvimento desta pesquisa, cujo objeto serão as cooperativas, com o diferencial de que o disclosure compulsório mínimo é menor que o das companhias abertas, ou seja, algumas das demonstrações contábeis que são obrigatórias para empresas de capital aberto são voluntárias para 
as cooperativas, como por exemplo a Demonstração do Valor Adicionado (DVA). Com isso, foram selecionados dois grupos de informações - sociais e ambientais - 11 categorias e 48 subcategorias.

O grupo composto pelas informações sociais está apresentado no Quadro 2 composto por três categorias e 14 subcategorias.

Quadro 2. Métrica para coletar informações sociais sobre o disclosure voluntário.

\begin{tabular}{|c|l|}
\hline Categoria & \multicolumn{1}{c|}{ Subcategoria } \\
\hline $\begin{array}{c}\text { Informações } \\
\text { Financeiras Sociais }\end{array}$ & $\begin{array}{l}\text { Demonstração do Valor Adicionado (DVA) } \\
\text { Menções ao valor adicionado ou distribuído } \\
\text { Investimentos de caráter social } \\
\text { Gastos em projetos sociais }\end{array}$ \\
\hline Produtos/Serviços & $\begin{array}{l}\text { Produtos/serviços da empresa estão adequados às normas de segurança } \\
\text { Menção a reclamação sobre produtos e/ou serviços }\end{array}$ \\
\hline Colaboradores & $\begin{array}{l}\text { Número de funcionários } \\
\text { Remuneração dos funcionários } \\
\text { Benefícios aos funcionários } \\
\text { (natisfação dos funcionários }\end{array}$ \\
Sadministradores) & $\begin{array}{l}\text { Informação sobre minorias na força de trabalho } \\
\text { Educação e treinamento dos funcionários } \\
\text { Segurança no local de trabalho } \\
\text { Relacionamento com sindicatos ou órgãos de classe }\end{array}$ \\
\hline
\end{tabular}

Fonte: Elaborado pelos autores com base em Murcia (2009).

O Quadro 3 apresenta o grupo composto pelas informações ambientais e está dividido em oito categorias e 34 subcategorias.

Quadro 3. Métrica para coletar informações ambientais sobre o disclosure voluntário.

\begin{tabular}{|c|l|}
\hline Categoria & \multicolumn{1}{|c|}{ Subcategoria } \\
\hline Políticas Ambientais & $\begin{array}{l}\text { Declaração das políticas, práticas, ações atuais } \\
\text { Estabelecimento de metas e objetivos ambientais } \\
\text { Compliance com a legislação ambiental } \\
\text { Parcerias, conselhos, fóruns ambientais } \\
\text { Prêmios e participações em índices ambientais }\end{array}$ \\
\hline $\begin{array}{c}\text { Gestão e Auditoria } \\
\text { Ambiental }\end{array}$ & $\begin{array}{l}\text { Gestão ambiental } \\
\text { ISOs 9000 } \\
\text { Auditoria Ambiental }\end{array}$ \\
\hline $\begin{array}{c}\text { Impactos dos Produtos e } \\
\text { Processos no Meio Am- } \\
\text { biente }\end{array}$ & $\begin{array}{l}\text { Desperdício e resíduos } \\
\text { Processo de acondicionamento (embalagem) } \\
\text { Reciclagem } \\
\text { Desenvolvimento de produtos ecológicos } \\
\text { Uso eficiente e/ou reutilização da água } \\
\text { Impacto no meio ambiente (vazamentos, derramamentos, terra utilizada } \\
\text { etc.) } \\
\text { Reparos aos danos ambientais }\end{array}$ \\
\hline Energia & $\begin{array}{l}\text { Conservação e/ou utilização mais eficiente nas operações } \\
\text { Utilização de materiais desperdiçados na produção de energia } \\
\text { Desenvolvimento ou exploração de novas fontes de energia }\end{array}$ \\
\hline $\begin{array}{c}\text { Educação e Pesquisa } \\
\text { Ambiental }\end{array}$ & $\begin{array}{l}\text { Investimentos ambientais } \\
\text { Custos e/ou despesas ambientais } \\
\text { Ativos ambientais intangíveis } \\
\text { Passivos ambientais }\end{array}$ \\
\hline $\begin{array}{l}\text { Práticas contábeis de itens ambientais } \\
\text { Seguro ambiental }\end{array}$ \\
\hline $\begin{array}{l}\text { Educação ambiental (internamente e/ou comunidade) } \\
\text { Pesquisas relacionadas ao meio ambiente }\end{array}$ \\
\hline
\end{tabular}




\begin{tabular}{|c|l|}
\hline $\begin{array}{c}\text { Mercado de Crédito de } \\
\text { Carbono }\end{array}$ & $\begin{array}{l}\text { Projetos de Mecanismos de Desenvolvimento Limpo (MDL) } \\
\text { Créditos de carbono } \\
\text { Emissão de Gases do Efeito Estuda (GEE) } \\
\text { Certificados de Emissões Reduzidas (CER) }\end{array}$ \\
\hline $\begin{array}{c}\text { Outras Informações Am- } \\
\text { bientais }\end{array}$ & $\begin{array}{l}\text { Menção relativa à sustentabilidade ou desenvolvimento sustentável } \\
\text { Gerenciamento de florestas e/ou reflorestamento } \\
\text { Conservação da biodiversidade } \\
\text { Relacionamento ambiental com stakeholders }\end{array}$ \\
\hline
\end{tabular}

Fonte: Elaborado pelos autores com base Murcia (2009)

\subsection{Análise de dados}

Devido ao fato de os relatórios terem modelos de divulgação muito distintos uns dos outros, inviabilizando selecionar um modelo único, optou-se por avaliar os dados de forma binária, ou seja, se a cooperativa divulga determinado dado recebe nota 1 , se não divulga recebe nota 0 . Dessa forma, verifica-se a existência, ou não, de determinada informação (KHANNA; PALEPU e SRINIVASAN, 2004). Os dados foram analisados com a apresentação das médias de divulgação por subcategorias e com base na obra de Schultz et al. (2013), o qual desenvolveu três índices aritméticos: Índice de Disclosure (ID), Índice de Disclosure das Empresas (IDE) e Índice Geral de Disclosure das Empresas (IGDE).

O Índice de Disclosure (ID) demonstra a quantidade de empresas que fazem divulgação em ao menos uma subcategoria da categoria avaliada, o que representa a aderência das empresas a alguma divulgação voluntária. O maior valor do índice é 1 (se todas as empresas evidenciaram informações) e o valor mínimo é 0 (se todas as empresas não evidenciaram nenhuma informação). A fórmula (1) utilizada foi a seguinte:

$$
D 1=E \div T
$$

em que, ID é o Índice de Disclosure, E é a quantidade de empresas que evidenciaram ao menos uma subcategoria das categorias avaliadas e T é o total de empresas da categoria.

O Índice de Disclosure das Empresas (IDE) representa o nível de evidenciação das empresas (E) que formam o índice ID. O maior valor do índice IDE é 1 (todas as empresas E evidenciaram informações que atendem todas as subcategorias da categoria) e o menor valor é $R>0$ (todas as empresas $E$ evidenciaram informações que atendem somente a uma subcategoria da categoria). A fórmula (2) que representa IDE é:

$$
I D E=D E \div(S C \times E)
$$

em que, DE é a quantidade de Disclosure ou evidenciação na categoria, SC a quantidade de subcategorias da categoria e $E$ a quantidade de empresas que evidenciou ao menos uma das subcategorias. Esse índice não pode ser comparado entre categorias diferentes.

O Índice Geral de Disclosure das Empresas corresponde à quantidade de evidenciações em relação ao total de empresas observadas de uma mesma categoria. O valor máximo deste índice é 1 (todas as empresas observadas apresentaram informações que atendem a todas as subcategorias da categoria) e o valor mínimo é 0 (nenhuma subcategoria da categoria é atendida pela divulgação). A fórmula (3) para este índice é apresentada a seguir: 


$$
I G D E=D E \div(S C \times T)
$$

em que, DE é a quantidade de evidenciações da categoria, SC a quantidade de subcategorias da categoria e T a quantidade total de empresas observadas na categoria.

Além disso, ampliou-se a metodologia com a comparação do índice geral de divulgação social e do índice geral de divulgação ambiental para verificar se existe diferença na divulgação voluntária das informações sociais e ambientais. A fórmula (4) calcula o Índice Geral de Disclosure social (IGDs) é:

$$
I G D s=D E s \div(S C s \times T)
$$

em que, IGDs é Índice Geral de Disclosure social, DEs é a quantidade de evidenciação total do grupo variáveis sociais, SCs é a quantidade total de subcategorias do grupo social e T é a quantidade total de empresas.

A fórmula (5) calcula o Índice Geral de Disclosure ambiental (IGDa) é:

$$
I G D a=D E a \div(S C a \times T)
$$

em que, IGDa é Índice Geral de Disclosure ambiental, DEa é a quantidade de evidenciação total do grupo variáveis ambientais, SCa é a quantidade total de subcategorias do grupo ambiental e T é a quantidade total de empresas.

\subsection{Restrições da Pesquisa}

A análise realizada nos relatórios das cooperativas envolve o julgamento do pesquisador. A métrica utilizada para avaliar os dados coletados não atribui pesos, dando a mesma importância para todas as informações divulgadas. Outra restrição a ser destacada é a não análise de Balanços Patrimoniais e Notas Explicativas, penalizando empresas por divulgar determinadas subcategorias como, por exemplo, ativos ambientais intangíveis, passivos ambientais, práticas contábeis de itens ambientais e seguro ambiental somente nos demonstrativos contábeis. Além disso, cabe ressaltar que a amostra trabalhada na pesquisa é intencional, logo, não probabilística, e o período estudado é restrito a um ano, por isso os resultados da pesquisa restringem-se às cooperativas estudadas.

\section{RESULTADOS}

A tabela 1 apresenta as médias de divulgação por subcategorias para que o leitor tenha uma visão mais detalhadas das informações que as cooperativas divulgam. Como pode ser observado, as informações de caráter social e de gastos com projetos apresentaram destaque em relação ao disclosure social. Além de ficar evidente que as empresas em sua maioria declaram informações quanto ao número de funcionários, benefícios e os investimentos em relação a educação e treinamento para os colaboradores, outra preocupação é em comunicar as ações de segurança no trabalho, provavelmente pelo fato da regulamentação em relação à segurança do trabalhador.

Tratando-se do disclosure ambiental, o destaque é com relação ao cumprimento da legislação ambiental e aos processos de educação ambiental, além de mencionar nos relatórios a preocupação com a sustentabilidade. 
Tabela 1. Média de disclosure das subcategorias.

\begin{tabular}{|c|c|c|c|c|c|c|}
\hline Categorias & Subcategorias (variáveis) & Obs & Mean & $\begin{array}{l}\text { Std. } \\
\text { Dev. }\end{array}$ & Min & Max \\
\hline \multirow{4}{*}{$\begin{array}{l}\text { Informações } \\
\text { Financeiras } \\
\text { Sociais }\end{array}$} & Demonstração do Valor Adicionado (DVA) & 23 & 0,435 & 0,507 & 0 & 1 \\
\hline & Menções ao valor adicionado ou distribuído & 23 & 0,435 & 0,507 & 0 & 1 \\
\hline & Investimentos de caráter social & 23 & 0,870 & 0,344 & 0 & 1 \\
\hline & Gastos em projetos sociais & 23 & 0,783 & 0,422 & 0 & 1 \\
\hline \multirow{2}{*}{$\begin{array}{l}\text { Produtos/ } \\
\text { Serviços }\end{array}$} & $\begin{array}{l}\text { Produtos/serviços da empresa estão adequados às nor- } \\
\text { mas de segurança }\end{array}$ & 23 & 0,478 & 0,511 & 0 & 1 \\
\hline & Menção à reclamação sobre produtos e/ou serviços & 23 & 0,130 & 0,344 & 0 & 1 \\
\hline \multirow{8}{*}{$\begin{array}{l}\text { Colabora- } \\
\text { dores (não } \\
\text { administra- } \\
\text { dores) }\end{array}$} & Número de funcionários & 23 & 0,826 & 0,388 & 0 & 1 \\
\hline & Remuneração dos funcionários & 23 & 0,522 & 0,511 & 0 & 1 \\
\hline & Benefícios aos funcionários & 23 & 0,652 & 0,487 & 0 & 1 \\
\hline & Satisfação dos funcionários & 23 & 0,087 & 0,288 & 0 & 1 \\
\hline & Informação sobre minorias na força de trabalho & 23 & 0,522 & 0,511 & 0 & 1 \\
\hline & Educação e treinamento dos funcionários & 23 & 0,913 & 0,288 & 0 & 1 \\
\hline & Segurança no local de trabalho & 23 & 0,696 & 0,470 & 0 & 1 \\
\hline & Relacionamento com sindicatos ou órgãos de classe & 23 & 0,391 & 0,499 & 0 & 1 \\
\hline \multirow{5}{*}{$\begin{array}{l}\text { Políticas } \\
\text { Ambientais }\end{array}$} & Declaração das políticas, práticas, ações atuais & 23 & 0,565 & 0,507 & 0 & 1 \\
\hline & Estabelecimento de metas e objetivos ambientais & 23 & 0,130 & 0,344 & 0 & 1 \\
\hline & Compliance com a legislação ambiental & 23 & 0,739 & 0,449 & 0 & 1 \\
\hline & Parcerias, conselhos, fóruns ambientais & 23 & 0,348 & 0,487 & 0 & 1 \\
\hline & Prêmios e participações em índices ambientais & 23 & 0,130 & 0,344 & 0 & 1 \\
\hline \multirow{3}{*}{$\begin{array}{l}\text { Gestão e } \\
\text { auditoria } \\
\text { Ambiental }\end{array}$} & Gestão ambiental & 23 & 0,261 & 0,449 & 0 & 1 \\
\hline & ISOs 9000 & 23 & 0,217 & 0,422 & 0 & 1 \\
\hline & Auditoria Ambiental & 23 & 0,000 & 0,000 & 0 & 0 \\
\hline \multirow{7}{*}{$\begin{array}{c}\text { Impactos dos } \\
\text { Produtos e } \\
\text { Processos } \\
\text { no Meio } \\
\text { Ambiente }\end{array}$} & Desperdício e resíduos & 23 & 0,348 & 0,487 & 0 & 1 \\
\hline & Processo de acondicionamento (embalagem) & 23 & 0,348 & 0,487 & 0 & 1 \\
\hline & Reciclagem & 23 & 0,435 & 0,507 & 0 & 1 \\
\hline & Desenvolvimento de produtos ecológicos & 23 & 0,261 & 0,449 & 0 & 1 \\
\hline & Uso eficiente e/ou reutilização da água & 23 & 0,391 & 0,499 & 0 & 1 \\
\hline & $\begin{array}{l}\text { Impacto no meio ambiente (vazamentos, derramamen- } \\
\text { tos, terra utilizada etc.) }\end{array}$ & 23 & 0,130 & 0,344 & 0 & 1 \\
\hline & Reparos aos danos ambientais & 23 & 0,304 & 0,470 & 0 & 1 \\
\hline \multirow{3}{*}{ Energia } & Conservação e/ou utilização mais eficiente nas operações & 23 & 0,565 & 0,507 & 0 & 1 \\
\hline & $\begin{array}{l}\text { Utilização de materiais desperdiçados na produção de } \\
\text { energia }\end{array}$ & 23 & 0,261 & 0,449 & 0 & 1 \\
\hline & Desenvolvimento ou exploração de novas fontes de energia & 23 & 0,348 & 0,487 & 0 & 1 \\
\hline \multirow{6}{*}{$\begin{array}{c}\text { Informações } \\
\text { Financeiras } \\
\text { Ambientais }\end{array}$} & Investimentos ambientais & 23 & 0,565 & 0,507 & 0 & 1 \\
\hline & Custos e/ou despesas ambientais & 23 & 0,217 & 0,422 & 0 & 1 \\
\hline & Ativos ambientais intangíveis & 23 & 0,000 & 0,000 & 0 & 0 \\
\hline & Passivos ambientais & 23 & 0,000 & 0,000 & 0 & 0 \\
\hline & Práticas contábeis de itens ambientais & 23 & 0,000 & 0,000 & 0 & 0 \\
\hline & Seguro ambiental & 23 & 0,000 & 0,000 & 0 & 0 \\
\hline \multirow{2}{*}{$\begin{array}{c}\text { Educação e } \\
\text { Pesquisa Am- } \\
\text { biental }\end{array}$} & Educação ambiental (internamente e/ou comunidade) & 23 & 0,696 & 0,470 & 0 & 1 \\
\hline & Pesquisas relacionadas ao meio ambiente & 23 & 0,304 & 0,470 & 0 & 1 \\
\hline
\end{tabular}




\begin{tabular}{cllllll}
\hline $\begin{array}{c}\text { Mercado de } \\
\text { Crédito de } \\
\text { Carbono }\end{array}$ & Projetos de Mecanismos de Desenvolvimento Limpo (MDL) & 23 & 0,174 & 0,388 & 0 & 1 \\
& Emissão de Gases do Efeito Estuda (GEE) & 23 & 0,043 & 0,209 & 0 & 1 \\
& Certificados de Emissões Reduzidas (CER) & 23 & 0,087 & 0,288 & 0 & 1 \\
\hline \multirow{2}{*}{$\begin{array}{c}\text { Outras Infor- } \\
\text { mações Am- } \\
\text { bientais }\end{array}$} & $\begin{array}{l}\text { Menção relativa à sustentabilidade ou desenvolvi- } \\
\text { mententável }\end{array}$ & 23 & 0,087 & 0,288 & 0 & 1 \\
\hline & Gerenciamento de florestas e/ou reflorestamento & $\mathbf{0 , 7 3 9}$ & $\mathbf{0 , 4 4 9}$ & $\mathbf{0}$ & $\mathbf{1}$ \\
& Conservação da biodiversidade & 23 & 0,522 & 0,511 & 0 & 1 \\
& Relacionamento ambiental com stakeholders & 23 & 0,565 & 0,507 & 0 & 1 \\
\hline
\end{tabular}

Fonte: dados da pesquisa.

Foram utilizadas as variáveis das categorias expostas nos Quadros 2 e 3 para quantificar os índices de Disclosure, conforme os gráficos de 1 a 3.

No Gráfico 1 são apresentadas as informações de Disclosure voluntário social das cooperativas agropecuárias brasileiras evidenciando nos índices ID e IGDE a existência de uma maior preocupação em divulgar informações financeiras sociais e sobre os colaboradores não administradores. Com relação ao IDE, as categorias informações financeiras e sociais e produtos/serviços apresentaram maior índice de evidenciação, o que leva a crer que as cooperativas têm uma maior preocupação em divulgar aspectos relacionados a essas variáveis.

Além disso, cabe ressaltar que determinadas subcategorias tiveram um índice muito baixo de divulgação, como é o caso da "menção à reclamação de produtos e serviços" e "satisfação dos funcionários", ocasionando um menor nível de divulgação do Índice Geral de Disclosure das Empresas das categorias produtos/serviços e colaboradores (não administradores) respectivamente, o que demonstra uma menor preocupação em divulgar esse tipo de informação ao usuário.

Gráfico 1. Informações de Disclosure voluntário social das cooperativas agropecuárias brasileiras

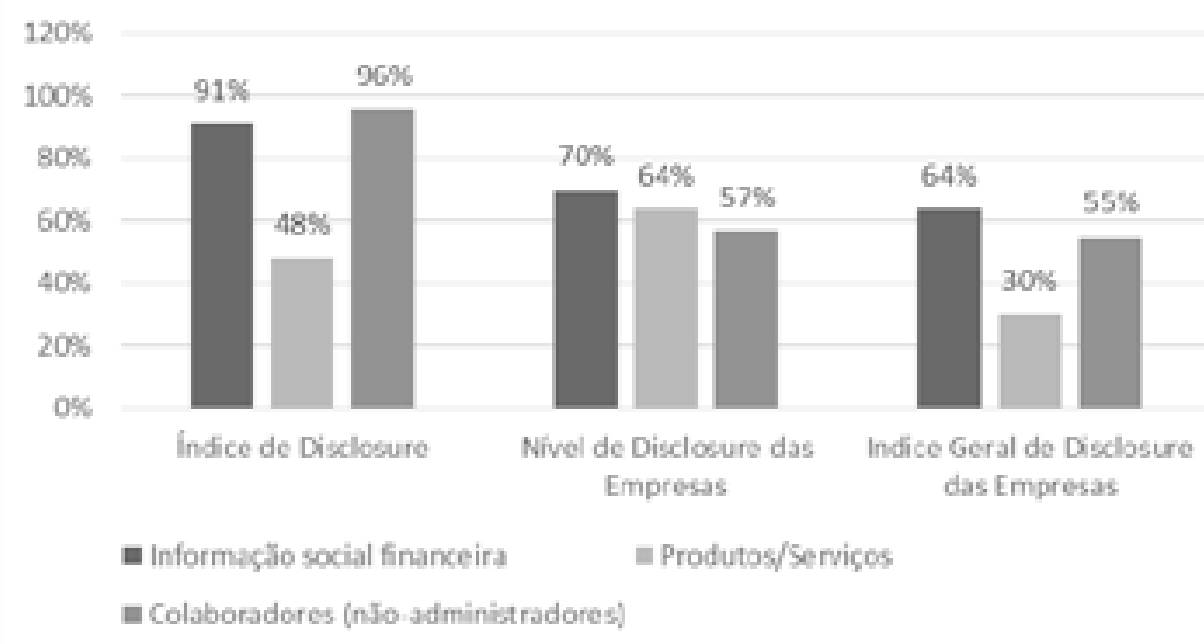

Fonte: Elaborado pelos autores.

No Gráfico 2 são apresentadas as informações de Disclosure voluntário ambiental das cooperativas agropecuárias brasileiras evidenciando no índice ID nas categorias "Políticas Ambientais" e "Informações Financeiras Ambientais", o maior nível de divulgação, logo, maior preocupação em divulgar esses assuntos. Em contrapartida, a categoria "Mercado de crédito de carbono" teve a menor divulgação do Índice ID, bem como no Índice IGDE, demonstrando uma menor preocupação em divulgar os feitos sobre esse tema. Com relação ao IDE, as categorias 
"Energia" e "Educação e Pesquisa Ambiental" apresentaram maior índice de evidenciação, o que leva a crer que as cooperativas têm uma maior preocupação em divulgar aspectos relacionados a essas variáveis. O Índice IGDE teve uma divulgação relativamente baixa, comparando aos outros índices, tendo em vista que a quantidade geral de divulgação das categorias atingiu no máximo $50 \%$ na categoria Educação e Pesquisa Ambiental.

Gráfico 2. Informações de Disclosure voluntário ambientais das cooperativas agropecuárias brasileiras.

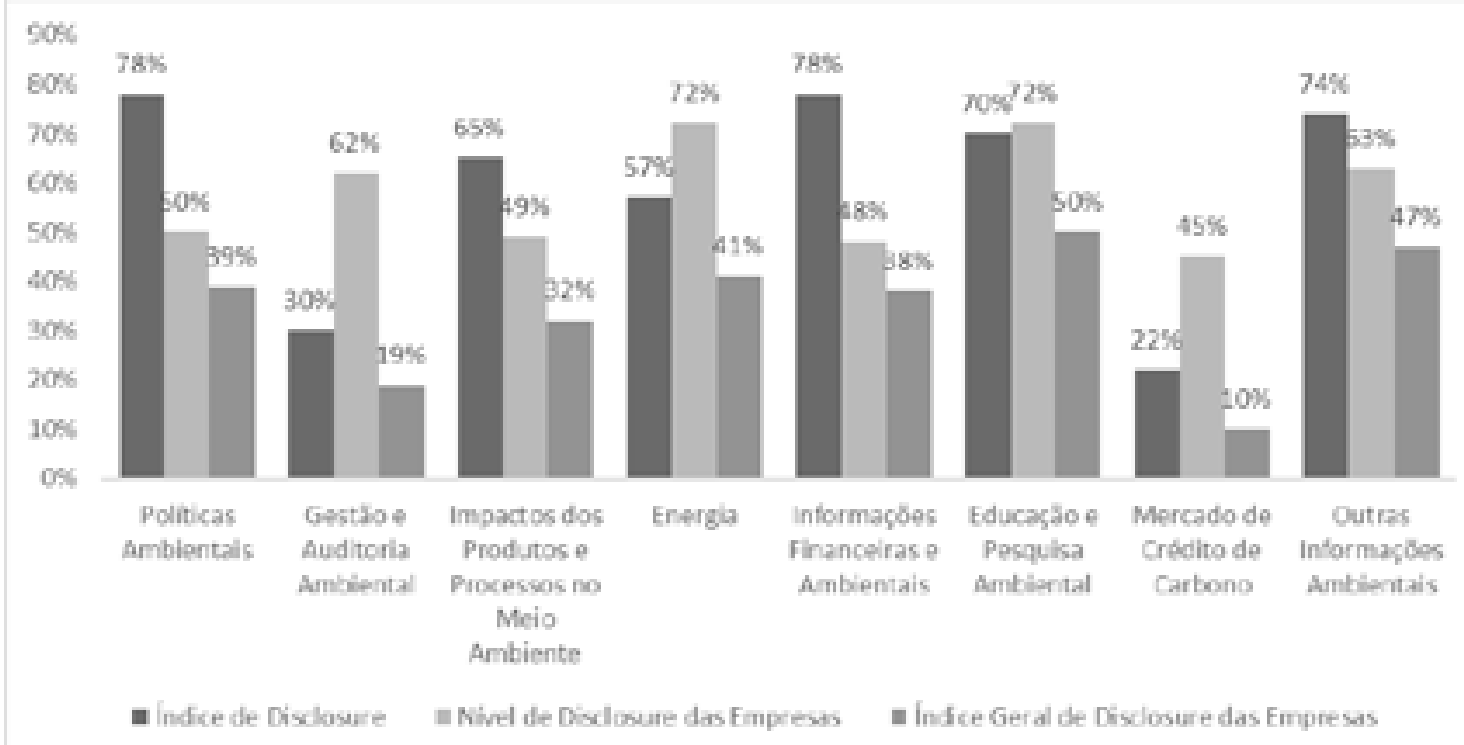

Fonte: Elaborado pelos autores.

No Gráfico 3 são apresentadas o Disclosure voluntário das informações sociais e ambientais das cooperativas agropecuárias brasileiras evidenciando de maneira geral maior divulgação de assuntos sociais do que ambientais, com uma diferença de 20 pontos percentuais, o que ressalta a preocupação com o sétimo princípio cooperativista: Interesse pela comunidade.

Gráfico 3. Informações de Disclosure voluntário das informações sociais e ambientais das cooperativas agropecuárias brasileiras.

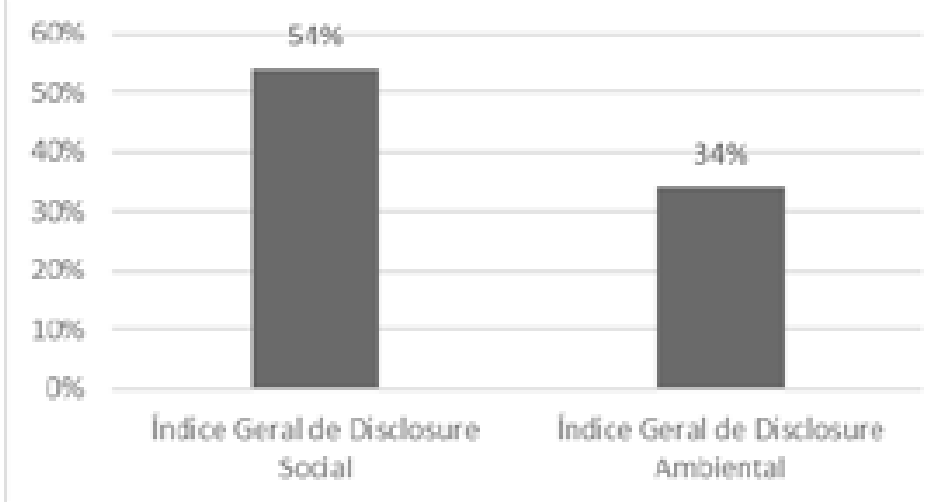

Fonte: Elaborado pelos autores.

A partir da análise do Gráfico 3, pode-se verificar que a média de disclosure geral (IGDs+lGDa/2) é 44\%, um percentual ainda baixo visto a importância de divulgar as práticas socioambientais da empresa cooperativa para os usuários da informação. 


\section{CONCLUSÕES}

Esta pesquisa teve como objetivo descrever o disclosure voluntário socioambiental em cooperativas agropecuárias brasileiras. $\mathrm{O}$ artigo se concentrou na análise dos relatórios anuais $\mathrm{e}$ similares do ano de 2015. A amostra foi retirada do ranking das "400 maiores empresas do agronegócio" da revista Exame. Foram verificadas as 62 cooperativas presentes no ranking supramencionado, porém, apenas 23 divulgaram relatório anual no site e foram, portanto, objeto da pesquisa.

Com base nas médias é possível observar um nível baixo de divulgação das informações socioambientais das cooperativas agropecuárias, mas com algum destaque para informações de cunho social, principalmente, ligadas a aspectos de preocupação com a comunidade local e com a educação, inclusive ambiental. Tal fato está de acordo com os princípios cooperativistas.

De acordo com a análise dos resultados da pesquisa, verifica-se que as cooperativas se preocupam mais em divulgar informações sociais do que ambientais. Dentre as informações sociais, a categoria que trata dos "colaboradores não administradores" foi a mais divulgada. Dentre as informações ambientais, as categorias "políticas ambientais e informações financeiras e ambientais" foram as mais mencionadas nos relatórios. Cabe ressaltar ainda que algumas informações sociais e ambientais, respectivamente, como "produtos e serviços" e "mercado de crédito de carbono" foram as menos divulgadas.

No entanto, analisando que das 62 cooperativas presentes no ranking consultado, apenas 23 divulgam informações socioambientais e das que divulgam o índice médio de divulgação fica abaixo de $50 \%$, esse fato demonstra a falta de preocupação das cooperativas agropecuárias brasileiras em fornecer informações aos usuários.

A principal contribuição da pesquisa foi a análise do disclosure voluntário socioambiental das cooperativas agropecuárias brasileiras, bem como a utilização de uma métrica abrangente e representativa, composta por 11 categorias e 48 subcategorias, que permite mensurar o nível de disclosure voluntário das cooperativas agropecuárias e provê evidências empíricas sobre o objeto de pesquisa, contribuindo para a literatura brasileira sobre o tema e para futuras pesquisas.

\section{REFERÊNCIAS}

AMRAN, A.; LEE, S. P.; DEVI, S. S. The influence of governance structure and strategic corporate social responsibility toward sustainability reporting quality. Business Strategy and the Environment, 2014.

BIALOSKORSKI NETO, S. Um ensaio sobre desempenho econômico e participação em cooperativas agropecuárias. Rev. Econ. Sociol. Rural, Mar 2007, vol.45, no.1, p.119-138.

BUSHMAN, R. M.; PIOTROSKI, JOSEPH D.; SMITH, A. J. What determines corporate transparency?. Journal of accounting research, v. 42, n. 2, p. 207-252, 2004.

Comitê de Pronunciamentos Contábeis, CPC- CPC 01. Demonstração do valor adicionado., v. 27, p. 11-05, 2016. Disponível em: < http://www. cpc. org. br/pdf/CPC_09. pdf>. Acesso em 10 dez. 2016. 
Cooperativas Brasileiras, Organização de - OCB. Agenda legislativa do cooperativismo, 2013. Disponível em: </http://www.brasilcooperativo.coop.br/Site/ocb_congresso/agenda_ cooperativismo_2013.pdf> acesso em: 30 de junho de 2017.

COSTA, M. I.; TORRES, L. S.; VASCONCELOS, A. C.; DE LUCA, M. M. M. Classificação do conteúdo dos relatórios de sustentabilidade de empresas premiadas por suas práticas de responsabilidade socioambiental. REPeC - Revista de Educação e Pesquisa em Contabilidade, Brasília, 7(2), art. 3, 147-166, abr./jun. 2013.

DANTAS, J. A.; ZENDERSKY, H. C.; NIYAMA, J. K. A dualidade entre os benefícios do disclosure e a relutância das organizações em aumentar o grau de evidenciação. Economia \& Gestão, v. 5, n. 11, p. 56-76, 2008.

DYE, R. A. An evaluation of essays on disclosure and the disclosure literature in accounting. Journal of Accounting and Economics, v. 32, n. 1, p. 181-235, 2001.

GAWLAK, A.; RATZKE, F. A. Cooperativismo: primeiras lições. 4. ed. Brasília: Sescoop, 2010.

GIBBINS, M.; RICHARDSON, A.; WATERHOUSE, J. The management of corporate financial disclosure: opportunism, ritualism, policies, and processes. Journal of accounting research, $p$. 121-143, 1990.

HENDRIKSEN, E. S. V. B.; MICHAEL, F. Teoria da contabilidade, v. 1, 1999.

HOSSAIN, M. The extent of disclosure in annual reports of banking companies: The case of India. 2008.

INTERNATIONAL ACCOUNTING STANDARD COMMITTEE - IASC. Normas Internacionais de Contabilidade 2001. Tradução da obra International Accounting Standard 2001, coordenada pelo Ibracon. São Paulo: Ibracon, 2002.

International Co-operative Alliance (ICA). Co-operative identity, values \& principles. Disponível na internet: <https://ica.coop/en/what-co-op/co-operative--values-principles>, Acesso em: 20 agosto. 2017.

IUDÍCIBUS, S. Contabilidade Introdutória/Equipe de professores da faculdade de Economia, Administração e Contabilidade da USP. São Paulo: Atlas, 1998.

S.; MARTINS, E.; GELBCKE, E.. Manual de contabilidade das sociedades por ações: aplicável às demais sociedades. São Paulo: Atlas, 2007.

S. Manual de contabilidade societária: aplicável a todas as sociedades, de acordo com as normas internacionais e do CPC. Ed. Atlas, 2010.

S. Teoria da contabilidade. Atlas, 1980.

KHANNA, T.; PALEPU, K. G.; SRINIVASAN, S. Disclosure practices of foreign companies interacting with US markets. Journal of Accounting Research, v. 42, n. 2, p. 475-508, 2004.

LANG, M. H.; LUNDHOLM, R. J. Voluntary disclosure and equity offerings: reducing information asymmetry or hyping the stock? Contemporary accounting research, v. 17, n. 4, p. 623-662, 2000. 
LOPES, A. B.; IUDÍCIBUS, S. de; MARTINS, E. Teoria da contabilidade: uma nova abordagem. São Paulo: Atlas, 2005.

LORZA, A. L. La transparencia en las cooperativas: más transparencia es más participación. Derecom 16, 2014 , p.7.

MEDEIROS, O. R.; QUINTEIRO, L. G. L. Ambiente de evidenciação contábil e mobilidade de capitais internacionais. In: CONGRESSO USP DE CONTROLADORIA E CONTABILIDADE, 5., 2005, São Paulo. Anais... São Paulo: FEA/USP, 2005. CD-ROM.

MURCIA, Fernando Dal-Ri. "Fatores determinantes do nível de disclosure voluntário de companhias abertas no Brasil". 2009. 182 f. Tese (Doutorado em Ciências Contábeis) - Programa de Pós-Graduação em Ciências Contábeis, Departamento de Contabilidade e Atuária, Faculdade de Economia, Administração e Contabilidade da Universidade de São Paulo, São Paulo, 2009.

MURCIA, F. Dal-Ri; DOS SANTOS, Ariovaldo. Fatores determinantes do nível de disclosure voluntário das companhias abertas no Brasil. Revista de Educação e Pesquisa em Contabilidade, v. 3, n. 2, p. 72-95, 2009.

RUFINO, M. A.; MACHADO, M. R. Fatores Determinantes da Disclosure de Informações Voluntárias Social: Evidências Empíricas no Brasil. In: Congresso USP de Controladoria e Contabilidade, 15, 2015, São Paulo. Anais... São Paulo: 2015.

SAMPAIO, M. S.; GOMES, S. M. S.; BRUNI, A. L.; DIAS FILHO, J. M. Evidenciação de Informações Socioambientais e Isomorfismo: um estudo com mineradoras brasileiras. Revista Universo Contábil, v. 8, p. 105-122, 2012.

SCHULTZ, C. A.; DE OLIVEIRA MARQUES, T.; MURCIA, F. D. R.; HOFER, E. Disclosure voluntário de informações ambientais, econômicas e sociais em cooperativas do setor agropecuário. TPATeoria e Prática em Administração, v. 2, n. 2, p. 56-77, 2013.

VERRECCHIA, R. E. Essays on disclosure. Journal of accounting and economics, v. 32, n. 1, p. 97180, 2001.

YAMAMOTO, M. M; SALOTTI, B. M. Informação contábil: estudos sobre a sua divulgação no mercado de capitais. Atlas, 2006. 